Lois Presser and Sveinung Sandberg (eds.)

\title{
Narrative Criminology: Understanding Stories of Crime
}

New York University Press, New York and London, 2015, (ISBN: 978-1-4798-7677-8), 318 pp.

Reviewed by: Christopher Birkbeck, University of Salford, UK.

If the 'narrative turn' describes the emergence of a corresponding subfield in each of the social sciences ('narrative sociology', 'narrative psychology,' etc.), then 'narrative criminology' has appeared on the scene at a fairly late stage. In that regard, it is positioned to draw on insights and methods from a vast field of inquiry and make the case for narrative as an important and putatively neglected perspective for understanding matters of crime and justice. In this volume, Lois Presser and Sveinung Sandberg bring together a set of contributions designed to do just that. They are prefaced by an introductory exposition setting out the origins, content and hopes for this 'exciting new field of study' (Back Cover) and followed by some thoughts on the way forwards. In between are ten chapters that cover a variety of behaviours (sex offending, drug trafficking, drug use, robbery, tax evasion and forced relocation), countries (Canada, Ecuador, Italy, Norway, the United Kingdom, the United States), data sources (interviews, historical documents, newspapers, autobiography) and analytical approaches (ethnographic, thematic, text, conversational).

The editors define their field in terms of two key delimiters. First, they equate narratives with stories (temporal sequencings of events); second, they propose that narratives can cause crime. The first delimiter probably looks unobjectionable; the second, somewhat more innovative. Both are something of a straitjacket. Stories appear with regularity throughout the book, rarely in extended form (there would not be the space to include them) usually in shorthand or embryonic form (which is often the way they are relayed in conversation). For example, in Fleetwood's chapter, we are told that many women in the Ecuadorian prison told stories about their journey into drug smuggling; while Sandberg and Tutenges' cannabis users told stories about their good and bad experiences with 
drug use. However, quite a few of the narrative segments in the text are not stories at all, but commentaries on events. Thus, Ugelvik's prisoners denigrated sex offenders through indignation ('We can't have people like that here. It's fucking sickening!' [30]); while Miller et al.'s recovering meth users excoriated the source of their addiction ('I mean meth is so toxic, it's so caustic, it's just disgusting.' [84]). The editors rightly recognise that narrative accomplishes a great deal of moral work, but their contributors' materials show that the most explicit moral work often emerges in nonstoried discourse. Should commentary be defined outside narrative and excluded from analysis?

Moral work, indeed, is at the heart of much of the talk examined in this book. Its significance for identity is acknowledged throughout, particularly in the first four chapters which are organised under the heading 'Stories Construct Proper Selves.' (It is a pity, perhaps, that no contributor looked for narratives of the improper self, so adroitly rendered by Katz [1988] in his Seductions of Crime.) But what about the editors' claim that stories cause crime? Is this substantiated by the case studies that are offered? As Miller et al. shrewdly comment, a 'key methodological challenge for narrative criminology...[lies in the fact that]...most accounts collected by criminologists are retrospective' $(90)$. Accordingly, much of the focus of narrative criminologists is retrospective, with the complication that stories will vary over time and by audience. The narratives in this collection reveal something about the changing assessments of self and experience and, in O'Connor's intriguing chapter on narrative 'hotspots,' the potential openings for therapeutic interventions that might lead to 'ways of changing the self' (188). But it is much harder to establish a clear line of sight between stories and criminal behaviour, and to establish the location of identity within this analytical framework.

Narrative Criminology offers a passable introduction to the study of narrative in criminology for those who know little about it. But for those who have studied the narrative turn in other fields, the book is likely to elicit a number of critical comments. Why does narrative criminology proceed with only minimal reference to methods and insights from the broader field of narrative studies? Why is 
the focus only on offending, thereby leaving aside the rich literatures on narratives of victimhood, reconciliation and justice? If the emphasis is to be on stories, why are poetics not taken into account? How can the causal role of stories be adequately demonstrated? Criminologists will recognise that in one way or another attention to talk has been around for a long time (e.g., in techniques of neutralisation). How much is new in this narrative criminology and how much is it recycling what otherwise would be billed as ethnography, frame analysis, or thematic analysis?

\section{Reference}

Katz J (1988) Seductions of Crime. New York: Basic Books. 